\title{
Prevalence, antibiotic susceptibility profile and extended spectrum $\beta$-lactamase production among Escherichia coli from high vaginal swab (HVS)
}

\author{
Adegoke, Anthony A.* and Okoh, Anthony I. \\ Applied and Environment Microbiology Research Group (AEMREG), Department of Biochemistry and Microbiology, \\ University of Fort Hare, Alice, South Africa. \\ Accepted 18 July, 2011
}

\begin{abstract}
We examined the prevalence, antibiotic susceptibility profile and extended spectrum $\beta$ - lactamase (ESBL) production by transitory Escherichia coli among other bacteria in vagina of female patients with symptoms of urinary tract infection, using standard microbiological methods. One hundred and fortyfour patients' samples were collected, of which 123 isolates were recovered. The age of the patients ranged from 8 to 62 years, while the mean was 28.5. Twenty-nine isolates of $E$. coli (that is, $22.9 \%$ prevalence) was recovered, while other bacterial species and their frequencies of occurrence include Bacillus spp. (6.3\%), Micrococcus spp. (2.1\%), Staphylococcus aureus (12.5\%), Streptococcus spp. (2.1\%), Gardnerella spp. (20.8\%), Lactobacillus spp. (62.5\%), Escherichia vulneris (2.1\%), Enterococcus spp. (4.2\%), Arachnia spp (2.1\%) and they exhibited resistance to various antibiotics. $E$. coli exhibited 22 to $78 \%$ resistance to ampicillin, cotrimoxazole, gentamycin, nitrofurantoin, colistin, tetracycline, nalidixic, ciprofloxacin, ofloxacin. Twenty $E$. coli isolates showed ESBL production by phenotypic confirmatory test and were resistant to third generation oral and parenteral cephalosporins as treatment options. High concomitant recovery of E. coli along with Gardnerella spp. (and Streptococcus spp.) among the divorcees and single parents showed that it might be sexually transmitted. The results also reiterate the relevance of nitrofurantoin in treatment of the genital bacterial infection. Therefore, it is imperative to screen and confirm ESBL production by any organism that showed resistance to the second and third generation Cephalosporins in a routine diagnostic laboratory work, though sanitary prophylaxis is preferentially recommended to prevent the entrance of difficult to-treat ESBL producers.
\end{abstract}

Key words: Vagina, prevalence, antibiotic, resistance, extended spectrum $\beta$-lactamase, Escherichia coli.

\section{INTRODUCTION}

Multidrug Escherichia coli isolates have been implicated usually as the most prevalent in myriads of clinical cases (Odusanya, 2002; Olowe et al., 2008; Rajini et al., 2008; Okonko et al., 2009). In vagina, it is usually next to Lactobacillus spp., which is regarded as important flora with high importance in non-specific immunity. Factors often responsible for $E$ coli resistance include R-factor on plasmids, resistance genes on the chromosomes, production of $\beta$-lactamase, extended spectrum $\beta$ lactamase enzymes (Bo, 1991; Aboderin et al., 2009).

${ }^{\star}$ Corresponding author. E-mail: aadegoke@ufh.ac.za or anthonyadegoke@yahoo.co.uk.
Though the presence $E$. coli in vagina is regarded as transient due to the vagina's proximity to the anus, yet in this state, they can either get established and cause urinary tract infection in nearby urinary passage or washed out with urine (or menstrual flow) (Profet, 1993). The extended spectrum $\beta$-lactamase (ESBL) producing $E$. coli are difficult to treat due to their resistance to wide spectrum of antibiotics including the third generation cephalosporin. They are of peculiar concern in this research because of their public health implications when they successfully invade the urinary tract and/or reproductive system, causing urinary tract infection or venereal disease. Meanwhile, the scourge of multidrug resistant ESBL producing $E$. coli is global. In Pakistan, Ullah et al. (2009) reported that E. coli isolated from 
Table 1. Sample distribution and bacterial isolates recovery per age.

\begin{tabular}{ccccc}
\hline \multirow{2}{*}{ Age range (Years) } & \multicolumn{2}{c}{ Samples obtained } & \multicolumn{2}{c}{ Isolates recovery } \\
\cline { 2 - 5 } & No. & $\%$ & No. & $\%$ \\
\hline $8-12$ & 19 & 13.2 & 13 & 10.6 \\
$13-17$ & 37 & 25.7 & 22 & 17.9 \\
$18-44$ & 62 & 43.1 & 45 & 36.5 \\
$45-62$ & 26 & 18.0 & 43 & 35.0 \\
Total & 144 & 100 & 123 & 100 \\
\hline
\end{tabular}

urinary tract infections (UTI) are multidrug resistant and produces ESBL. Also in Spain, 51\% ESBL producing $E$. coli were isolated from outpatients in a nationwide study. In Nigeria, a study in Western part of the country isolated quite a number of ESBL producing $E$. coli (Aibinu et al., 2003). This research also followed the trend of assessment of venereal diseases and urinary tract infections earlier carried out within the study area (Uyo). In an instance, Akinjogunla and Adegoke (2009) observed that the sero-prevalence of HIV infection in Uyo, Akwa Ibom State, Nigeria was reported to be $34.17 \%$, which made the state ranked 4th in Nigeria. Venereal diseases are also reportedly rampant in the metropolis (Hassan et al., 2002).

Adegoke et al. (publication in press) observed that $E$. coli was the most prevalent in studies on symptomatic urinary tract infection and asymptomatic bacteriuria also in Uyo with higher prevalence in female than male. This research served as a follow up of these earlier researches.

\section{MATERIALS AND METHODS}

\section{Description of sampling area}

The study sampling took place at three laboratories: Life Link Medical Laboratory, Our Lady of Lourdes Maternity and infirmary, and Standard Medical Laboratory which are major referral laboratories for major private hospitals in Uyo, Akwa Ibom State, Nigeria.

\section{Study population, sampling technique and isolation}

Only patients who came in person and agreed to fill the questionnaires were considered for this study and their biometry was obtained using a questionnaire. High vaginal swab samples were obtained from patients with complaint of itching, lower abdominal waist pain, vaginal discharge disorder, and urinary tract infections using cotton-tipped applicators.

It was preserved under ice and immediately analyzed by conventional cultural methods, microscopic observation, microbial physiology, haemolysis of blood and biochemical characterizations (Cheesebrough, 2006).

Identification of the entire bacterial proximate composition and the prevalence of $E$. coli amidst other isolates, including the frequency of occurrence per sample were calculated.

\section{Antibiotic susceptibility testing (AST)}

The choice of the antibiotics was informed by frequent prescription in the area from our previous study (unpublished). The antibiotics considered to be inhibitors of the cell wall synthesis (penicillin, ampicillin, cefotaxime, cefpodoxime, augmenting, amoxycillin), protein synthesis (gentamycin, streptomycin, tetracyclines, chloramphenicol and erythromycin), and nucleic acid synthesis (nalidixic acid, ciprofloxacin, ofloxacin and cotrimoxazole) were utilized for inhibition tests. This was carried out using the scheme of Cheesebrough (2006).

\section{Extended spectrum $\beta$-lactamase test in $E$. coli}

\section{Double disc synergistic test}

Mueller Hinton agar plates were prepared and inoculated with inoculums from 0.5 McFarland equivalents standard of $E$. coli. Thirty microgram's disc of cefotaxime $(30 \mu \mathrm{g})$ and cefpodoxime (10 $\mu \mathrm{g})$ antibiotics were placed on the agar at a distance of $15 \mathrm{~mm}$ center to center from a combination disc of Augmentin (amoxicillin $20 \mu \mathrm{g}$ and clavulanic acid $10 \mu \mathrm{g}$ ) in triplicates. E. coli ATCC 25922 and E. coli ATCC 35218 were used as a negative control and a positive control, respectively. ESBL production was interpreted by using the scheme of CLSI (2008).

\section{RESULTS}

One hundred and forty-four samples obtained contained 123 isolates which include Bacillus spp., Micrococcus spp, Staphylococcus aureus, Streptococcus spp., Gardnerella spp., Lactobacillus spp., E. coli, Escherichia vulneris, Enterococcus spp., and Arachnia spp. The mean age of the patients was 28.5 while the range was 8 to 62 years. They were all outpatients. The summary of the samples collected and isolates recovered per ages of the individuals are presented in Table 1. Table 2 consists of the information marital status, sample collection and isolate recovery among the marriageable individuals, 18 to 62 years group with the individuals from whom the samples were obtained along with numerical isolates (polymicrobial or monomicrobial). Frequencies of occurrence of the $E$. coli along with other isolates were depicted on Table 3 while the effectiveness of antibiotic against other isolates was placed in Table 4. E. coli was $78,65,52,22,60,58,60 \%, 56,48$ and $45 \%$ resistant to 
Table 2. Marital status, sample collection and isolate recovery among the marriageable individuals (18 to 62 years).

\begin{tabular}{lccccl}
\hline \multirow{2}{*}{ Status } & \multicolumn{3}{c}{ Samples collected } & \multicolumn{3}{c}{ Isolates recovery } & \multirow{2}{*}{ Other observation } \\
\cline { 2 - 5 } & No. & $\%$ & No. & $\%$ & \\
\hline Unmarried (single parent) & 16 & 18.2 & 20 & 22.7 & 9 Polymicrobial / 5 did not grow \\
Married & 28 & 31.8 & 20 & 22.7 & 6 Polymicrobial / some samples did not grow \\
Single & 17 & 19.3 & 14 & 15.9 & Polymicrobial/some did not grow \\
Widow & 7 & 8.0 & 4 & 4.6 & Monomicrobial \\
Divorcee & 8 & 9.1 & 17 & 19.3 & Polymicrobial \\
Cohabiter & 12 & 13.6 & 13 & 14.8 & 2 Polymicrobial / 1 sample was sterile \\
Total & 88 & 100 & 88 & 100 & \\
\hline
\end{tabular}

Table 3. Frequency of occurrence of bacteria isolate in HVS sample obtained.

\begin{tabular}{lc}
\hline Bacteria isolate & Percentage of samples bacteria containing isolates obtained \\
\hline Bacillus spp. & 6.3 \\
Arachnia spp. & 2.1 \\
Enterococcus spp. & 4.2 \\
E. coli & 22.9 \\
Escherichia vulnaris & 2.1 \\
Gardnerella spp. & 20.8 \\
Lactobacillus spp. & 62.5 \\
Micrococcus spp. & 2.1 \\
S. aureus & 12.5 \\
Streptococcus spp. & 2.1 \\
\hline
\end{tabular}

Table 4. Effectiveness of antibiotics used with respect to other isolates in percentage.

\begin{tabular}{cccc}
\hline $\begin{array}{c}\text { Gram positive drug } \\
\text { (Concentration) }(\boldsymbol{\mu g})\end{array}$ & Effectiveness (\%) & $\begin{array}{c}\text { Gram negative drug } \\
\text { (Concentration) }(\boldsymbol{\mu g})\end{array}$ & Effectiveness $(\%)$ \\
\hline Aug (30) & 68.6 & Amp $(10)$ & 16.7 \\
Amx (25) & 54.9 & Cot $(25)$ & 33.3 \\
Ery (5) & 75.4 & Gen (10) & 91.7 \\
Tet (10) & 82.6 & Nal (30) & 75.0 \\
Cxc (5) & 26.1 & Nit & 83.3 \\
Gen (10) & 92.8 & Col (10) & 41.7 \\
Cot (25) & 21.6 & Str (10) & 50.0 \\
Chl (30) & 85.5 & Tet (10) & 58.3 \\
Amp (10) & 15.8 & & \\
Pen (11) & 0 & & \\
Str (10) & 89.5 & & \\
\hline
\end{tabular}

Aug, Augmentin; Amx, amoxicillin; Ery, erythromycin; Tet, tetracycline; Cxc, cloxacillin; Gen, gentamicin; Cot, cotrimoxazole; Chl, chloramphenicol; Amp, ampicillin; Pen, penicillin; Str, streptomycin; Nit, nitrofuratoin; Col, colistin.

ampicillin, cotrimoxazole, gentamycin, nitrofurantoin, colistin, streptomycin, tetracycline, nalidixic, ciprofloxacin, and ofloxacin respectively. The resistant profile of $E$. coli to the conventional antibiotics of frequent prescription in the area was depicted in Figure 1. All the twenty E. coli isolates that were resistant to $\beta$-lactam antibiotics and the $3^{\text {rd }}$ generation cephalosporin were positive to phenotypic confirmatory extended spectrum $\beta$-lactamase test.

\section{Extended spectrum $\beta$-lactamase}

All the resistant $E$. coli to $\beta$-lactam antibiotics that were selected for the double disk synergistic test using 


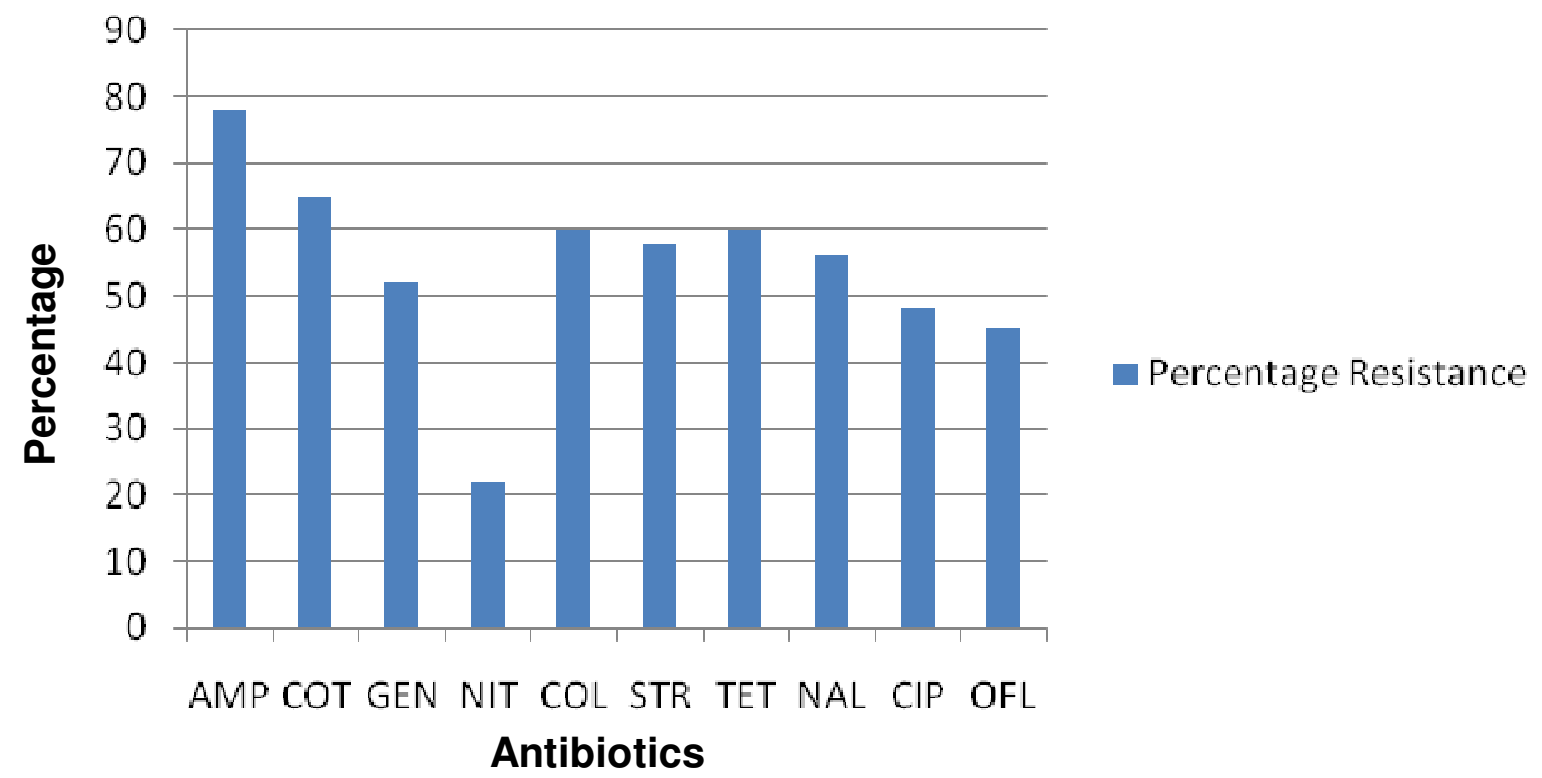

Figure 1. High resistance levels of E. coli to antibiotics used in percentage. Aug, Augmentin; Amx, amoxicillin; Ery, erythromycin; Tet, tetracycline; Cxc, cloxacillin; Gen, gentamicin; Cot, cotrimoxazole; Chl, chloramphenicol; Amp, ampicillin; Pen, penicillin; Str, streptomycin; Nit, nitrofuratoin; Col, colistin.

cefotaxime, cefpodoxime and augmentin showed positive presumptive result for the production of extended spectrum beta lactamase.

\section{DISCUSSION}

Quite large numbers of potential pathogens (beside the $E$. coli) were recovered in the course of this research from the vaginal pathway. These organisms were relative aetiologies of the symptoms experience by the patients as they (besides Lactobacilli) have earlier been implicated in urinary tract infection with the peculiar symptoms (Noor et al., 2004; Ciesielski, 2010; Anon, 2011).

There is high possibility that these organisms were either washed by mechanical action during urination to the vulvo-vaginal pathway or spread from the vagina to the point of infection, prior to the observed clinical manifestations. Infection was obvious in most of these patients as there were observation of febrile and or frequent urination in them as febrile could be as a result of body's immunological response to infection (Adegoke and Komolafe, 2009). The occurrence of $E$. coli in vagina may not always be connected with UTI but the proximity of the short urethra allows ease of passage of pathogens from the vagina to the bladder. This research however is really not meant to study UTI but $E$. coli amidst vagina bacterial load. Since the respondents in this research are all with relative UTI symptoms, the high frequency of occurrence and resistance to conventional antibiotics like $\beta$-lactam antibiotics, cotrimoxazole, tetracycline and even to fluoroquinolone like nalidixic acid by the $E$. coli coupled with resistance to third generation oral cephalosporin (cefpodoxime) and parenteral cephalosporin (cefotaxime) leaves much to be desired. Only nitrofurantoin showed appreciable effectiveness as a therapeutic option in case of none. Infection from such an extended spectrum $\beta$-lactamases (ESBLs) producers might be difficult to treat (Ulla et al., 2009). This observation agrees with the observation of Aboderin et al. (2009).

Many of the $E$. coli isolates were from the children of age 8 to 12, single parents and divorcees which might be presumptively adduced to low hygiene in the children, indecent sexual habit among the single parents and divorcee. The high isolates in married individual seem high, though most of them have Lactobacillus spp. More research is on going to ascertain these occurrence as it might be mere co-incidence, but the co-infection with Gardnerella spp. and few with Streptococcus spp. in single parents and divorcee (unlike children) affirmed that it might be adduced to sexual transmission as the prevalence of Gardnerella spp. in male with women sexual partners have been reported (Schwebke et al., 2009). Meanwhile, it is therefore imperative for women to embrace sanitary prophylaxis that prevents the entrance of the E. coli (and Enterococcus spp.) to the vagina from anus and to also avoid indecent sexual habits that may contribute to vagina's bacterial load and in turn lead to urinary tract infection with difficult-to treat ESBLs producing bacteria. This test for ESBLs production by resistant bacteria should be incorporated into the routing and diagnostic laboratory. When not infected, medical 
prophylaxis should be avoided as it may induce bacterial resistance to infections. When already infected however, antibiotic sensitivity testing should always precede the administration of any antibiotic therapy to avoid abuse.

\section{REFERENCES}

Aboderin OA, Abdu A, Odetoyin BW, Lamikanra A (2009). Antimicrobial Resistance in Escherichia coli Strains from Urinary Tract Infections. J. Natl. Med. Assoc., 101: 1268-1273

Adegoke AA, Komolafe AO (2009). Multi-drug resistant Staphylococcus aureus in clinical cases in Ile-Ife, Southwest Nigeria. Int. J. Med. Med. Sci., 1(3): 068-072

Aibinu IE, Olaegbulam VC, Adenipakan EO, Ogunsola FT, Odugbemi JO, Mee BJ (2003). Extended spectrum $\beta$-lactamase enzymes in clinical isolates of Enterobacteria species from Lagos. Nig. J. Clin. Microbiol., 41: 2197-2200

Akinjogunla OJ, Adegoke AA (2009). Sero-Prevalence of Human Immunodeficiency Virus (HIV) 1 and 2 nfections in Uyo Metropolis, Akwa Ibom State. Sci. Res. Essay, 4(6): 590-593

Anon (2011). Urinary Tract Infections in Infants and Children in Developing Countries in the Context of $\mathrm{IMCl}$. Downloaded on http://whqlibdoc.who.int/hq/2005/WHO_FCH_CAH_05.11.pdf on 12th Feb., 2011

Bo WT (1991). Bacteriological Study Of High Vaginal Swabs In Pregnant Women In Evangel Hospital. Hong Kong Pract., 13(9): 1673-1677

Cheesebrough M (2006). District Laboratory Practice in tropical countries. Part 2, Second edition. Cambridge university press, 35-70: 132-143.

Ciesielski GL (2010).Clinical Indicators of Urosepsis: a retrospective study of Geriatric Emergency Department admissions Accessed on $17^{\text {th }}$ December onhttp://www.nursing.arizona.edu/Library/Ciesielski_Gail_Practice Inquiry.pdf

Clinical Laboratory Standards Institute (2008). Performance Standards for Antimicrobial Susceptibility Testing; Eighteen Informational Supplement. Wayne, PA: National Committee for Clinical Laboratory Standards, 28(1): M100-S118.
Hassan C, Olawoye J, Nnadozie K (2002). Impact of International Trade and Multinational Corporations on the Environment and Sustainable Livelihoods of Rural Women in Akwa-lbom State, Niger Delta Region, Nigeria. Accessed on 17th December, 2010 on http://depot.gdnet.org/cms/conference/papers/4th_prl 5.5.3_comfort_ hassan_paper.pdf

Noor N, Ajaz M, Rasool SA, Pirzada ZA (2004). Urinary tract infections associated with multidrug resistant enteric bacilli: characterization and genetical studies. Pak. J. Pharm. Sc., 17(2): 115-123

Odusanya OO (2002). Antibiotic susceptibility of microorganisms at a General Hospital in Lagos, Nigeria. J. Natl. Med. Assoc., 94: 994998.

Okonko IO, Soleye FA, Amusan TA, Ogun AA, Ogunnusi TA, Ejembi J (2009). Incidence of Multi-Drug Resistance (MDR) Organisms in Abeokuta, Southwestern Nigeria. Glob. J. Pharmacol., 3(2): 69-80

Olowe OA, Okanlawon BM, Olowe RA, Olayemi AB (2008). Antimicrobial resistant pattern of Escherichia coli from human clinical samples in Osogbo, south western Nigeria. Afr. J. Microbiol. Res., 2: 008-011

Profet M (1993). Menstruation as a defense against pathogens transported by sperm. Q. Rev. Biol., 68(3): 335-386

Rajini E, Sherwal BL, Anuradha (2008). Detection of ExtendedSpectrum $\beta$-lactamases in AmpC $\beta$-lactamase-Producing Nosocomial Gram-negative Clinical Isolates from a Tertiary Care Hospital in Delhi. Indian J. Doctor.http://www.indmedica.com/journals.php?journalid=3\&issueid= 123\&articleid $=1626 \&$ action=article.

Schwebke JR, Rivers C, Lee J (2009). Prevalence of Gardnerella vaginalis in Male Sexual Partners of Women With and Without Bacterial Vaginosis. Sex. Transm. Dis., 36(2): 92-94

Ullah F Malik SA, Ahmed J (2009). Antibiotic susceptibility pattern and ESBL prevalence in nosocomial Escherichia coli from urinary tract infections in Pakistan. Afr. J. Biotechnol., 8(16): 3921-3926 